\title{
NEGATIVE APPENDECTOMIES ARE MORE COMMON IN FEMALES OF REPRODUCTIVE AGE GROUP
}

\author{
Zahid Ali, Muhammad Rahil Khan, Riyasat Ahmed Memon, Ikram Din Ujjan, Fida Hussain, Zainab Nisar
}

\author{
Liaquat University of Medical and Health Sciences, Hyderabad Pakistan
}

\begin{abstract}
Objective: To compare the negative appendectomy in the females of reproductive and non-reproductive age groups.

Study Design: Cross-sectional study.

Place and Duration of Study: Department of Pathology, Diagnostic and Research Laboratory, Liaquat University of Medical and Health Sciences, Hyderabad, Pakistan, from January 2018 to December 2019.

Methodology: A total of 1126 appendectomy specimens were enrolled irrespective of age and gender. The biodata of patients was retrieved from the database. Statistical analysis was done using SPSS version 22.

Results: Out of total 1126 reported cases, 787 (69.9\%) were males and $339(30.1 \%)$ were females. The mean age was calculated to be $24.43 \pm 12.42$ years ranging from 2-94 years. Histopathological examination revealed cases of acute appendicitis 374 $(33.2 \%)$, acute appendicitis with peri-appendicitis $478(42.5 \%)$, fibrous obliteration $28(2.5 \%)$ and parasitic infestation $7(0.6 \%)$. Overall negative appendectomies were 219 (19.4\%) and were prominent in females $100(29.5 \%)$ than males 119 (15.1\%). Also it was higher in females of reproductive age group 77 (30.4\%) than in non-reproductive age group $23(27.9 \%)$.

Conclusion: In our study negative appendectomy in females of reproductive age groups was found to be higher than expected. Clinical scoring systems, biochemical markers, imaging modalities, and second opinion from other specialties like internal medicine, gynae and obstetric have been introduced to substantiate the diagnosis of acute appendicitis and thereby decreases the negative appendectomy.
\end{abstract}

Keywords: Acute appendicitis, Appendectomy, Negative appendectomy.

How to Cite This Article: Ali Z, Khan MR, Memon RA, Ujjan ID, Hussain F, Nisar Z. Negative Appendectomies Are More Common in Females of Reproductive Age Group. Pak Armed Forces Med J 2021; 71(6): 2011-2014. Doi: https://doi.org/10.51253/pafmj.v6i6.4630

\footnotetext{
This is an Open Access article distributed under the terms of the Creative Commons Attribution License (https://creativecommons.org/licenses/by-nc/4.0/), which permits unrestricted use, distribution, and reproduction in any medium, provided the original work is properly cited.
}

\section{INTRODUCTION}

Appendectomy is the most commonly performed operation in surgical emergency units globally as acute appendicitis (AA) is considered to be a frequent differential diagnosis in acute abdomen. ${ }^{1}$ Average risk of developing AA in the general population is $7-10 \%$ with the utmost tendency to present in the second and third decades of life. ${ }^{2}$ The rate of appendectomies in developing countries is still higher than in developed countries as it is misdiagnosed as acute appendicitis due to lack of diagnostic modalities especially in health centers of rural areas. ${ }^{3}$

Usual clinical presentation of acute appendicitis is fever, right iliac fossa pain, guarding, rigidity with rebound tenderness, and vomiting. ${ }^{4}$ But occasionally it becomes difficult to diagnose clinically in women of reproductive age as gynecological pathologies like ovarian cysts, ectopic pregnancy, complicated abortions, and acute salpingitis also share the same sign and symptoms. ${ }^{5}$ Therefore despite well-known clinical findings for years still several medical and surgical diseases

Correspondence: Dr Zahid Ali, Resident of Pathology, Malir Clinic Naukot, Taluka Judho District, Mirpur Khas, Sindh-Pakistan Received: 11 Jul 2020; revision received: 07 Dec 2020; accepted: 14 Dec 2020 closely mimic appendicitis consequential in establishing a false diagnosis in a significant number of patients causing the removal of the macroscopically or histopathologically normal appendix referred as negative appendectomy. ${ }^{6}$

Currently, there is no single accepted negative appendicectomy rate (NAR) worldwide. Multiple studies carried worldwide reported that NAR ranges from $4-45 \% .^{7}$ According to a local study, its rate is $14 \%$ in Pakistan. ${ }^{8}$ Introduction of Alvarado score and use of imaging tools like Ultrasonography, magnetic resonance imaging, and Focused appendiceal computed tomography (FACT) has its role in diagnosis preoperatively, ${ }^{9}$ but histopathological examination is still the gold standard for diagnosis. This study was designed to determine the negative appendectomy in females and to identify a particular age group having its higher rate which will help to prevent removal of normal appendix by identifying the cause behind it thereby reducing the rate of negative appendectomy.

\section{METHODOLOGY}

This cross-sectional study was conducted in the Diagnostic and Research Laboratory, Pathology Department, Liaquat University of Medical and Health 
Sciences, Sindh, Pakistan from the period of January 2018 to December 2019. Sample size was calculated by using Open-Epi online software for sample size calculator. The prevalence of negative appendectomy in Pakistan is $14 \% .{ }^{10}$ By keeping this value as a reference with 95\% confidence level and 5\% margin of error, the sample size of 185 was calculated. Prior to this study approval was taken from the Institutional Review Board and the non-probability consecutive technique was used for sampling.

Inclusion Criteria: Clinically suspects of inflamed appendix from all age groups of both gender who went under appendectomy were included and specimens sent to the histopathology department for biopsy.

Exclusion Criteria: Specimens with autolytic changes and appendix removed incidentally during other abdominal or pelvic surgeries were excluded.

Relevant clinical data, gross findings and histopathologic reports were retrieved from pathology logbook and computer databases. Slides were obtained from the histopathology department and microscopy was performed by histopathologists to verify the diagnosis.

Data was analyzed on Microsoft Excel 2010 and Statistical Package for the social sciences (SPSS) version 23. Descriptive statistical test was used to calculate frequencies, percentage, mean and standard deviation. Quantitative data such as age were expressed as mean and standard deviation while qualitative such as histopathological findings were expressed as frequency and percentage. Chi-square test was applied to determine the significant association between the gender, age groups and negative appendectomy rate. The $p$-value of $\leq 0.05$ was considered significant.

\section{RESULTS}

A total of 1126 patients who matched the inclusion criteria were studied. The mean age was 24.4 \pm 12.42 years ranging from 2-94 years. Of the total 1126 patients, $787(69.9 \%)$ were males while 339 (30.1\%) female cases were reported. Histopathological analysis revealed acute appendicitis as the commonest finding in the male group followed by acute appendicitis with periappendicitis and fibrous obliteration while removal of normal appendix was frequently observed in females. A single male case of appendicular diverticulum was also reported. Neoplastic lesions were also seen including 7 cases of Low-grade Mucinous Neoplasm (LAMN) predominantly in males. In malignant lesions, two cases of mucinous adenocarcinoma followed by one case of carcinoid tumor and metastatic carcinoma were also encountered. Gender wise frequencies of different histopathological lesions are shown in Table-I.

Table-I: Categorical distribution of histopathological findings based on frequency and gender.

\begin{tabular}{|c|c|c|c|}
\hline $\begin{array}{l}\text { Histopathological } \\
\text { Findings }\end{array}$ & Males & Females & Total \\
\hline \multicolumn{4}{|l|}{ Normal Histology } \\
\hline Normal Appendix & $119(15.1 \%)$ & $100(29.5 \%)$ & $219(19.4 \%)$ \\
\hline \multicolumn{4}{|l|}{ Anatomic Abnormalities } \\
\hline Fibrous Obliteration & $16(2 \%)$ & $12(3.5 \%)$ & $28(2.5)$ \\
\hline Diverticulum & $1(0.1 \%)$ & - & $1(0.1 \%)$ \\
\hline \multicolumn{4}{|c|}{ Inflammatory Conditions } \\
\hline Acute Appendicitis & $260(33 \%)$ & $114(33.6 \%)$ & $374(33.2 \%)$ \\
\hline $\begin{array}{l}\text { AA with Peri- } \\
\text { appendicitis }\end{array}$ & $\begin{array}{c}378 \\
(48 \%)\end{array}$ & $\begin{array}{c}100 \\
(29.5 \%)\end{array}$ & $\begin{array}{c}478 \\
(42.5 \%)\end{array}$ \\
\hline Tuberculosis & $6(0.8 \%)$ & $2(0.6 \%)$ & $8(0.7 \%)$ \\
\hline \multicolumn{4}{|l|}{ Parasitic Infestation } \\
\hline $\begin{array}{l}\text { Enterobius } \\
\text { Vermicularis }\end{array}$ & $2(0.3 \%)$ & $5(1.5 \%)$ & $7(0.6 \%)$ \\
\hline \multicolumn{4}{|l|}{ Neoplastic Lesions } \\
\hline $\begin{array}{l}\text { Low Grade Mucinous } \\
\text { Neoplasm }\end{array}$ & $4(0.5 \%)$ & $3(0.9 \%)$ & $7(0.6 \%)$ \\
\hline $\begin{array}{l}\text { Mucinous } \\
\text { Adenocarcinoma }\end{array}$ & $1(0.1 \%)$ & $1(0.3 \%)$ & $2(0.2 \%)$ \\
\hline Carcinoid & - & $1(0.3 \%)$ & $1(0.1 \%)$ \\
\hline Metastatic Carcinoma & - & $1(0.3 \%)$ & $1(0.1 \%)$ \\
\hline
\end{tabular}

Overall negative appendectomy was found in 219 $(19.4 \%)$ patients with a higher occurrence in females $100(29.5 \%)$ as compared to males $119(15.1 \%)$. Moreover, numbers are significant $(p<0.05)$ in women of reproductive age group than in non-reproductive age group shown in Table-II.

Table-II: Age group distribution and negative appendectomy.

\begin{tabular}{|c|c|c|c|c|}
\hline \multirow{2}{*}{ Gender } & \multirow{2}{*}{$\begin{array}{c}\text { Age Group } \\
\text { (years) }\end{array}$} & \multicolumn{2}{|c|}{ Appendectomy (n) n (\%) } & \multirow{2}{*}{$\begin{array}{c}p- \\
\text { value }\end{array}$} \\
\hline & & Positive & Negative & \\
\hline \multirow{3}{*}{ Female } & $\begin{array}{c}\text { Non } \\
\text { Reproductive } \\
<14 \text { to }>45 \text { years }\end{array}$ & $63(72.1)$ & $23(27.9)$ & 0.047 \\
\hline & $\begin{array}{l}\text { Reproductive } \\
\text { (15-45 years) }\end{array}$ & $176(69.9)$ & $77(30.4)$ & 0.029 \\
\hline & Overall & $239(70.5)$ & $100(29.5)$ & 0.034 \\
\hline Male & Overall & $668(84.9)$ & $119(15.1)$ & 0.053 \\
\hline
\end{tabular}

\section{DISCUSSION}

This study was conducted to analyze the negative appendectomy cases in females and to compare similar studies conducted throughout the globe. An inflamed appendix is mostly the clinically significant reason for patients to undergo its removal as for treatment. Histopathological examination is mandatory for confirmation of provisional clinical diagnosis as resected 
appendix has a wide range of spectrum from confirmation of acute appendicitis to unusual pathological conditions like tuberculosis, neuroendocrine tumors, lowgrade mucinous neoplasm or adenocarcinoma. ${ }^{10}$ According to our study acute appendicitis was high in males than in females with peak occurrence in the 2nd and $3^{\text {rd }}$ decade of life. Lohar et al, 11 and Jat et al, ${ }^{12}$ also reported the same in their studies. Removal of the appendix without any significant abnormality is generally described as a negative appendectomy. Unusual clinical presentation and lack of diagnostic tools play an important role in their unnecessary resections in rural health centers where surgeons have to rely only on physical findings. Its incidence is more among reproductive females due to many gynecological problems that mimic the similar sign and symptoms. In our study overall negative appendectomy was reported to be $19.4 \%$ with significantly higher rate in females (29.5\%) than males (15.1\%). Furthermore, we analyzed negative appendectomy in different age groups found higher than expected rates in reproductive females (30.4\%) than non-reproductive age group (27.9\%) which was similar to an Indian study conducted by Joshi et al, 7 studies carried out by Chooti et al,13 in Canada (16.7\%), Maria-dason et al, ${ }^{14}$ in USA (14.1\%) and Alhamdani, ${ }^{15}$ in Saudi Arabia (16.2\%) showed low negative appendectomy in females of the reproductive age group. While Brockman et al, ${ }^{16}$ from Australia $(23 \%)$, Mohebbi, ${ }^{4}$ from Iran $(23.4 \%)$ and Joshi et al, ${ }^{7}$ from India $(33.3 \%)$ reported relatively higher negative appendectomies.

Unnecessary removal of normal appendix not only increases the financial burden of patients but they are also exposed to unwanted adverse events of anesthesia, surgery, hospital-acquired infections, and unresolved actual pathology which causing acute abdomen. 17-18 All these events raising concerns to make efforts to decrease NAR thereby decrease morbidity and mortality. Therefore, a proper detailed clinical history, careful physical examination with the help of scoring systems, and the use of specific diagnostic tools may be helpful to make a clinical diagnosis of acute appendicitis. Furthermore, a multi-departmental approach involving other specialties likes internal medicine, urology, gynecology and obstetrics is necessary to exclude other pathologies before making the final decision to resect the appendix.

\section{CONCLUSION}

Histopathological examination is the gold standard and necessary for confirmation of provisional clinical diagnosis of every surgically removed appendix. In our study removal of normal appendix was among common findings and data showed a relatively high negative appendectomy in females of reproductive age group than non-reproductive age group. Clinical scoring systems, biochemical markers, imaging modalities and second opinion from other specialties may be helpful to confirm the diagnosis of AA and thereby decrease negative appendectomy.

\section{Conflict of Interest: None.}

\section{Authors' Contribution}

ZA: Conception, acquisition, study design, proof reading, MRK: Study design, literature review, practical work, RAM: Practical work, critical review, interpretation, IDU: Data processing, supervision, final approval, FH: Drafting, data collection, literature reviw, $\mathrm{ZN}$ :

\section{REFERENCES}

1. Snyder MJ, Guthrie M, Cagle S. Acute appendicitis: efficient diagnosis and management. Am Fam Phys 2018; 98(1): 25-33.

2. Biondi A, Di Stefano C, Ferrara F, Bellia A, Vacante M, Piazza L. Laparoscopic versus open appendectomy: a retrospective cohort study assessing outcomes and cost-effectiveness. World J Emerg Surg 2016; 11(1): 44-50.

3. Al-Omran M, Mamdani M, McLeod RS. Epidemiologic features of acute appendicitis in Ontario, Canada. Can J Surg 2003; 46(4): 263-268.

4. Mohebbi HA, Mehrvarz S, Kashani MT, Kabir A, Moharamzad Y. Predicting negative appendectomy by using demographic, clinical, and laboratory parameters: a cross-sectional study. Int J Surg 2008; 6(2): 115-118.

5. Hatipoglu S, Hatipoglu F, Abdullayev R. Acute right lower abdominal pain in women of reproductive age: clinical clues. World J Gastroenterol 2014; 20(14): 4043-4049.

6. Lim J, Pang Q, Alexander R. One year negative appendicectomy rates at a district general hospital: A retrospective cohort study. Int J Surg 2016; 31(1): 1-4.

7. Joshi MK, Joshi R, Alam SE, Agarwal S, Kumar S. Negative appendectomy: an audit of resident-performed surgery. how can its incidence be minimized? Indian J Surg 2015; 77(Suppl-3): 913917.

8. Jalil A, Shah SA, Saaiq M, Zubair M, Riaz U, Habib Y. Alvarado scoring system in prediction of acute appendicitis. J Coll Physicians Surg Pak 2011; 21(12): 753-755.

9. Cağlayan K, Günerhan Y, Koç A, Uzun MA, Altınlı E, Köksal N. The role of computerized tomography in the diagnosis of acute appendicitis in patients with negative ultrasonography findings and a low Alvarado score. Ulus Travma Acil Cerrahi Derg 2010; 16(5):445-448.

10. Charfi S, Sellami A, Affes A, Yaïch K, Mzali R, Boudawara TS. Histopathological findings in appendectomy specimens: a study of 24,697 cases. Int J Colorectal Dis 2014; 29(8): 1009-1012.

11. Lohar H, Asger Calcuttawala M, Nirhale D, Athavale V, Malhotra M, Priyadarshi N. Epidemiological aspects of appendicitis in a rural setup. Med J DY Patil Univ 2014; 7(6): 753-757.

12. Jat MA, Al-Swailmi FK, Mehmood Y, Alrowaili M, Alanazi S. Histopathological examination of appendicectomy specimens at a district hospital of Saudi Arabia. Pak J Med Sci 2015; 31(4): 891894.

13. Chooi WK, Brown JA, Zetler P, Wiseman S, Cooperberg P. Imaging of acute appendicitis and its impact on negative appendectomy and perforation rates: the St. Paul's experience. Can Assoc Radiol J 2007; 58(4): 220-224. 


\section{Negative Appendectomies}

14. Mariadason JG, Wang WN, Wallack MK, Belmonte A, Matari H. Negative appendicectomy rate as a quality metric in the management of appendicitis: impact of computed tomography, Alvarado score and the definition of negative appendicectomy. Ann $\mathrm{R}$ Coll Surg Engl 2012; 94(6): 395-401.

15. Alhamdani YF, Rizk HA, Algethami MR, Algarawi AM, Albadawi RH, Faqih SN, et al. Negative appendectomy rate and risk factors that influence improper diagnosis at king abdulaziz university hospital. Mater Sociomed 2018; 30(3): 215-220.
16. Brockman SF, Scott S, Guest GD, Stupart DA. Does an acute surgical model increase the rate of negative appendicectomy or perforated appendicitis?. ANZ J Surg 2013; 83(10): 744-747.

17. Vaghela K, Shah B. Diagnosis of acute appendicitis using clinical alvarado scoring system and computed tomography (CT) criteria in patients attending gujarat adani instituteof medical science - a retrospective study. Polish J Radiol 2017; 82(1): 726-730.

18. Sartelli M, Baiocchi GL, Di Saverio S, Ferrara F, Labricciosa FM. Prospective observational study on acute appendicitis worldwide (POSAW). World J Emerg Surg 2018; 13(1): 19-22. 